DOI: 10.12731/2070-7568-2018-1-105-115

УДК 338.48

\title{
СОДЕРЖАНИЕ ИНФОРМАЦИОННОГО КОМФОРТА В ГОСТИНИЧНОМ ПРЕДПРИЯТИИ
}

\author{
Радысина Е.Г.
}

Обслуживание в гостинице невозможно без организаџии обмена информачией между потребителями и производителями гостиничных услуг. Качество, полнота, доступность и достоверность информации влияет на создание информационного комфорта, который в свою очередь оказывает влияние на удовлетворенность и лояльность гостей. Статья посвящена рассмотрению видов информаџии, определяющей создание информационного комфорта в гостиничном предприятии. Вся информащия, воспринимаемая гостем в процессе обслуживания, делится на два больших блока: внешнюю и внутреннюю информаџию по отношению к гостинище. Внешняя информачия оказывает влияние на взаимоотношения потребителей и производителей гостиничных услуг, но само они на ее содержание повлиять не могут. Внутренняя информация представляет собой все, что формируется самой гостиницей на основании требований потребителей. Правильная организация предоставляемой гостям информации влияет на психологическое восприятие гостем прочесса обслужсивания.

Ключевые слова: комфорт; информация; информачионный комфорт; внешняя и внутренняя информация; гостиница.

\section{CONTENTS OF THE INFORMATION COMFORT IN HOTEL ENTERPRISE}

\section{Radygina E.G.}

Service in hotel impossible without organization of the exchange by information between consumer and producer of the hotel services. The 
Quality, fullness, accessibility and validity to information influences upon making the information comfort, which in turn influences on complacency and loyalty of the guests. The Article dedicated to consideration type to information, defining making the information comfort in hotel enterprise. The Whole information perceived by guest in process of the service, divided on two greater blocks: external and internal information to hotel. External information influences on relations of the consumers and producers of the hotel services, but itself they on its contents to affect can not. Internal information presents itself all that is formed most hotel on the grounds of requirements of the consumers. The Correct organization provided to guest to information influences upon psychological perception by guest of the process of the service.

Keywords: comfort; information; information comfort; external and internal information, hotel.

Сфера гостиничного обслуживания является информационнонасыщенной отраслью экономики, в которой взаимодействие потребителей и производителей гостиничного продукта происходит посредством обмена информацией. Информационные потоки включают в себя ассортимент и характеристики услуг, персональные данные гостей, финансовые потоки и т.п. Предоставление необходимой информации гостям также может являться частью обслуживания, например, предоставление информации о культурных мероприятиях и экскурсионных программах, предоставляемых гостям отеля.

Между участниками рынка гостиничных услуг существуют информационные взаимосвязи, в которых особое внимание уделяется точности, достоверности и востребованности информации. В настоящее время в процессе обслуживания на первый план выходит проблема обеспечения комфортности пребывания в гостинице и такой его составляющей, как информационный комфорт.

Несмотря на широкое употребление термина «информация» в литературных источниках, оно является одним из самых дискуссионных понятий. Существуют несколько подходов: функциональный, атрибутивный и антропоцентрический. С точки зрения 
функционального подхода, информация трактуется как сообщение, передаваемое по каналам связи (К.Э. Шеннон, Ю.М. Каныгин, И. Яглом). С позиции атрибутивного подхода, информация воспринимается как содержание, внутренняя характеристика объекта или процесса (Н. Винер, В.И. Корогодин, Э. Шредингер). Антропоцентрический подход концентрирует внимание на интерпретации потребителем полученного сообщения и субъективности отношения к информации (С.А. Бешенков, Е.А. Ракитина, И.Г. Семакин). В данном исследовании информация рассматривается с точки зрения антропологического подхода: «информация - это смысл, содержание сообщений, получаемых человеком из внешнего мира посредством его органов чувств» [12]. Логическим отображением такого понимания информации становится информационное взаимодействие между субъектами обслуживания (потребителем и обслуживающим персоналом), способствующее возникновению чувства комфорта у потребителя.

Под комфортом понимается чувство удовлетворенности гостя, вызываемое удобством окружающих условий, обстановки и обслуживания. Комфорт рассматривается с двух позиций: во-первых, как комплекс благоприятных условий окружающей среды, в которых человек находится в состоянии наименьшего психического и физического напряжения; или, во-вторых, как положительное психологическое состояние, связанное с субъективной оценкой внешних условий [3]. В гостиничном обслуживании выделяют следующие направления комфорта: информационный, экономический, эстетический, бытовой, комфорт безопасности, психологический комфорт [9, с. 241-242]. Информационный комфорт связан с содержанием внешней и информации о гостинице (буклеты, рекламные носители, веб-сайт) и внутренней информации, предоставляемой гостю (папка гостя, уголок потребителя, система пиктограмм и указателей, компетентность персонала) [5, с. 83]. Информационный комфорт связан в первую очередь с качеством и оперативностью предоставления информации гостю в гостинице и за ее пределами. 
В экономической сфере выделяют несколько видов информации:

- деловая информация, включающая информацию о компании, направлениях ее деятельности, продуктах и услугах, деловых связях и др.;

- научно-техническая информация, включающая данные фундаментальных и прикладных исследований, а также профессиональную информацию в сфере туризма и гостеприимства;

- массово-потребительская информация, включающая новости, справочную информацию, информацию для потребителей и развлекательную информацию (погода, расписание транспорта и т.д.) [10, с. 114].

Создание информационного комфорта начинается с предоставления наиболее полной информации об отеле, подразделении питания и других объектах гостиничной инфраструктуры еще до момента бронирования. Здесь очень важную роль играет размещение визуальной информации: фотографий с интерьером помещений, информации о комплексе предоставляемых основных и дополнительных услуг, стоимости услуг, наличии сертификатов безопасности и др. Во время проживания в гостинице гость сталкивается с другими элементами информационного комфорта. Структура информации о предприятии, влияющая на уровень информационного комфорта, представлена в табл. 1. Она включает информацию о стране и регионе и информацию о предприятии и услугах. Информация о стране и регионе носит по отношению к предприятию внешний характер, ни гостиница, ни потребитель не может повлиять на содержание этой информации, но она оказывает сильное влияние на их взаимодействие. Информация о предприятии и услугах носит внутренний характер и формируется гостиничным предприятием на основе изучения потребностей и запросов потребителей.

Информация, полученная гостем до посещения гостиничного предприятия, формирует его представления о гостиничном продукте, затем, уже при размещении в гостинице, сформированное представление оказывает влияние на восприятие всей окружающей обстановки и качества предоставляемых услуг. Таким образом, ин- 
формация, предоставляемая гостю, должна быть достоверной и не формировать неоправданных ожиданий, иначе гость не будет доволен обслуживанием.

Таблицча 1.

\section{Структура внешней и внутренней информации}

\begin{tabular}{|c|c|c|}
\hline $\begin{array}{c}\text { Вид инфор- } \\
\text { мации }\end{array}$ & Тип информации & Особенности \\
\hline \multirow[t]{4}{*}{$\begin{array}{l}\text { Внешняя } \\
\text { информация } \\
\text { (о стране и } \\
\text { регионе) }\end{array}$} & $\begin{array}{l}\text { Макроэкономиче- } \\
\text { ская и геополитиче- } \\
\text { ская информация }\end{array}$ & $\begin{array}{l}\text { Уровень инфляции, темпы экономического } \\
\text { развития региона, колебания курсов валют, } \\
\text { уровень политической и социальной ста- } \\
\text { бильности региона, стратегические про- } \\
\text { граммы правительства }\end{array}$ \\
\hline & $\begin{array}{l}\text { Рыночная инфор- } \\
\text { мация }\end{array}$ & $\begin{array}{l}\text { Объем и темпы роста рынка, покупатель- } \\
\text { ная способность, спрос и поведение по- } \\
\text { требителей, информация о конкурентах и } \\
\text { поставщиках }\end{array}$ \\
\hline & $\begin{array}{l}\text { Внешняя финансо- } \\
\text { вая информация }\end{array}$ & $\begin{array}{l}\text { Динамика курсов акций, движение на рын- } \\
\text { ке капитала }\end{array}$ \\
\hline & $\begin{array}{l}\text { Информация о регу- } \\
\text { лировании и налого- } \\
\text { обложении }\end{array}$ & $\begin{array}{l}\text { Система стандартов, ГОСТов и других } \\
\text { нормативно-правовых актов, регулирую- } \\
\text { щих деятельность предприятия, налоги и } \\
\text { льготы }\end{array}$ \\
\hline \multirow{4}{*}{$\begin{array}{l}\text { Внутренняя } \\
\text { информация } \\
\text { (о предпри- } \\
\text { ятии и услу- } \\
\text { гах) }\end{array}$} & $\begin{array}{l}\text { Информация о про- } \\
\text { изводстве }\end{array}$ & $\begin{array}{l}\text { Наличие производственных мощностей, } \\
\text { количество и категории номеров, виды } \\
\text { предприятий питания и дополнительного } \\
\text { обслуживания }\end{array}$ \\
\hline & $\begin{array}{l}\text { Информация о тру- } \\
\text { довых ресурсах }\end{array}$ & $\begin{array}{l}\text { Обучение персонала и уровень квалифика- } \\
\text { ции, моральное состояние персонала и до- } \\
\text { брожелательность по отношению к гостям }\end{array}$ \\
\hline & $\begin{array}{l}\text { История и описание } \\
\text { стратегии предпри- } \\
\text { ятия }\end{array}$ & $\begin{array}{l}\text { История предприятия, процесс производ- } \\
\text { ства в ретроспективе, миссия и стратегия } \\
\text { развития предприятия, истории взаимодей- } \\
\text { ствия с потребителями }\end{array}$ \\
\hline & $\begin{array}{l}\text { Внутренняя инфор- } \\
\text { мация }\end{array}$ & $\begin{array}{l}\text { Отчетность и обязательства компании, со- } \\
\text { циальная ответственность предприятия, } \\
\text { участие в социальных и благотворитель- } \\
\text { ных проектах }\end{array}$ \\
\hline
\end{tabular}

Одним из основных направлений повышения информационного комфорта на современном этапе развития общества является ис- 
пользование новых приемов и методов организации информационного обслуживания, внедрение новых информационных технологий. Самостоятельным компонентом формирования информационной среды предприятия является организация доступа к электронным ресурсам через сайт гостиницы. На сайте должна быть представлена вся информация, имеющая отношение к обслуживанию гостей. Важным с точки зрения потребителей является не только информационная насыщенность сайта гостиницы, но и организация навигации по сайту, его функциональность, а также организация обратной связи и взаимодействия с потребителями через сайт. Оперативное изменение информации и ответы на обращения вызывают большее доверие потребителей.

Внутренний информационный комфорт обеспечивается не только доступом к сайту и другим электронным информационным системам, но и с помощью материальных (системы указателей и пиктограмм, полиграфической продукции) и нематериальных (информированность и информативность персонала предприятия). При оформлении информации внимание необходимо уделять также оформлению и логотипизации объектов, содержащих информацию. Грамотно выполненный логотип может многое поведать о гостиничном предприятии: о его местонахождении, уровне комфорта, архитектурном стиле, назначении, контингенте потребителей и т.д. Требуется масса усилий для того, чтобы создать гармонию между всеми элементами фирменного стиля: эмблемой, шрифтом, оформлением полиграфической продукции и т.д. $[1,3]$. Умело подобранная информация для гостей, размещенная в нужном месте, - это гарантия успешного функционирования всех служб дополнительного обслуживания в отеле.

Перечень информации, необходимой для размещения в гостиничном номере, является обязательным и прописан в правилах предоставления гостиничных услуг $[2,7]$. Информация, наличие которой влияет на создание информационного комфорта для гостей предприятия:

- Информация обо всех услугах, предоставляемых отелем, с указанием месторасположения соответствующих служб, ре- 
жима их работы, контактных телефонов, по услугам телефонной связи с полным перечнем расценок на телефонные переговоры, а также кодов стран и городов, о работе телевидения;

- Меню работы службы обслуживания на этажах (питание, дополнительные услуги) с указанием стоимости услуг, телефонов для осуществления заказа, перечень продуктов и напитков мини-бара с указанием расценок, количества продукции, а также порядка пользования мини-баром, бланк карты-заказа завтрака в номер;

- Бланк анкеты-отзыва для гостя о качестве обслуживания;

- Информация о мерах пожарной безопасности, памятка о порядке проживания в гостинице;

- Табличка-вывеска на дверь (разрешение/запрет уборки в номере;

- Карта города с указанием основных достопримечательностей и телефонов экстренных служб;

- Материалы с логотипом гостиницы (календарь с видом гостиницы, открытки, писчая бумага, блокноты для записей, конверты, ручки и др.).

Указатели, используемые в гостиницах, а также различные системы визуальной навигации тоже играют важную роль в создании информационного комфорта. Это своего рода гиды, указывающие гостям верное направление, составляющие системы навигации для гостиницы начиная с самого первого дорожного знака. Разработка дизайна системы знаков гостиницы нелегкая задача и представляет собой сложную систему визуальной навигации, учитывающую тенденции поведения гостей, корректное направление, особенности окружающей среды, специфику конструктивных элементов здания и многое другое [11]. Важно, чтобы вся визуальная информация соответствовала нормативным требованиям и была доступна для использования гостями с ограниченными возможностями [5, с. 207].

Таким образом, обеспечение информационного комфорта в гостинице становится отдельным направлением обслуживания потребителей. Информация становится важнейшим стратегическим 
ресурсом привлечения потребителей, достижения более высокого уровня их удовлетворенности и формирования лояльности. Информационные услуги переходят из разряда вспомогательного элемента в разряд самостоятельной дополнительной услуги, востребованной потребителями.

Информационный комфорт выступает как основополагающий инструмент в создании и предоставлении качественного гостиничного продукта. Именно поэтому руководству гостиничного предприятия необходимо обращать внимание на содержание внешней и внутренней по отношению к гостиничному комплексу информации. В структуре информационного комфорта можно выделить информацию, которую гость не будет ассоциировать с гостиничным предприятием, но которая будет влиять на комфортность его пребывания - это информация о регионе. На содержание этой информации гостиничное предприятие не может повлиять, но она будет оказывать влияние на его взаимодействие с гостем. Внутренняя же информация является необходимой, так как именно на основании этой информации у гостя будут формироваться ожидания перед употреблением гостиничного продукта, и соответственно оцениваться качество гостиничного продукта и формироваться удовлетворенность обслуживанием.

\section{Список литературы}

1. Dickson D., Ford R.C., Laval B. Managing real and virtual waits in hospitality and service organizations // The Cornell Hotel and Restaurant Administration Quarterly. 2005. T. 46. № 1. C. 52-68.

2. The evolution of the hospitality industry // The Cornell Hotel and Restaurant Administration Quarterly. 1985. T. 26. № 1. C. 36-86.

3. Yuksel A. Managing customer satisfaction and retention: a case of tourist destinations, Turkey // Journal of Vacation Marketing. 2001. T. 7. № 2. C. $153-168$.

4. Анисимов К.Г., Анисимова Е.А., Дронова Е.Н., Калинин А.В., Калинина Ю.А. Информационное обеспечение социальной сферы: оценка открытости и доступности // Наука Красноярья. 2017. Т. 6. № 4-2. С. $83-88$. 
5. Барабанова Н.А. Информационный комфорт как составляющая качества туристского обслуживания // Вестник Самарского университета. История, педагогика, филология. 2008. № 5-1 (64). С. 97-105.

6. Гаранин Н.И. Менеджмент безопасности в туризме и гостеприимстве: учебное пособие. М.: Советский спорт, 2005. 113 с.

7. Пережогина Н.С. Внешняя финансовая информация в деятельности гостиниц // Перспективы развития науки и образования: сборник научных трудов по материалам XVIII международной научно-практической конференции. 2017. С. 147-149.

8. Правила предоставления гостиничных услуг в Российской Федерации. Утв. Постановлением Правительства Российской Федерации № 1085 от 09.10.2015. Режим доступа: http://www.consultant. ru/document/cons_doc_LAW_187292/. Дата обращения: 06.01.2018.

9. Радыгина Е.Г. Направления обеспечения комфортных условий проживания в гостинице // Наука Красноярья. 2017. Т. 6. № 3-2. С. 239-260.

10.Рамзина С.А., Шабалова Н.Н., Семензато М. Коммуникативная безопасность в обеспечении информационного комфорта гостей // Стратегии обеспечения психологической безопасности в условиях неопределенности: Материалы V Международного симпозиума. 2014. С. 113-118.

11. Синицын, В. Интернет как средство для привлечения клиентов // Гостиничное дело. 2013. № 09. С. 50-55.

12. Фридланд А.Я. Информация: обзор современных представлений о сущности и подходов к определению // Федеральный портал «Единое окно доступа к образовательным ресурсам». Режим доступа: http://window.edu.ru/catalog/pdf2txt/804/58804/28666?p_page=3. Дата обращения: 23.02.2018.

\section{References}

1. Dickson D., Ford R.C., Laval B. Managing real and virtual waits in hospitality and service organizations. The Cornell Hotel and Restaurant Administration Quarterly. 2005. V. 46. № 1, pp. 52-68.

2. The evolution of the hospitality industry. The Cornell Hotel and Restaurant Administration Quarterly. 1985. V. 26. № 1, pp. 36-86. 
3. Yuksel A. Managing customer satisfaction and retention: a case of tourist destinations, Turkey. Journal of Vacation Marketing. 2001. V. 7. № 2, pp. $153-168$.

4. Anisimov K.G., Anisimova E.A., Dronova E.N., Kalinin A.V., Kalinina Yu.A. Nauka Krasnoyar'ya. 2017. V. 6. № 4-2, pp. 83-88.

5. Barabanova N.A. Vestnik Samarskogo universiteta. Istoriya, pedagogika, filologiya. 2008. № 5-1 (64), pp. 97-105.

6. Garanin N.I. Menedzhment bezopasnosti v turizme i gostepriimstve [Management to safety in tourism and hospitality: scholastic allowance]. M.: Sovetskiy sport, 2005. 113 p.

7. Perezhogina N.S. Perspektivy razvitiya nauki i obrazovaniya: sbornik nauchnykh trudov po materialam XVIII mezhdunarodnoy nauchnoprakticheskoy konferentsii [Prospects of the development of the science and formation: collection of the scientific works on material XVIII international scientifically-practical conference]. 2017, pp. 147-149.

8. The Rules of the granting the hotel services in Russian Federation. Utv. The Resolution Government to Russian Federation N 1085 from 09.10.2015. The Mode of the access: http://www.consultant.ru/document/ cons_doc_LAW_187292/. The Date of the address: 06.01.2018.

9. Radygina E.G. Nauka Krasnoyar ’ya. 2017. V. 6. № 3-2, pp. 239-260.

10. Ramzina S.A., Shabalova N.N., Semenzato M. Strategii obespecheniya psikhologicheskoy bezopasnosti v usloviyak neopredelennosti: Materialy V Mezhdunarodnogo simpoziuma [Strategies of the provision to psychological safety in condition of the uncertainties: Material V International symposium. 2014]. 2014, pp. 113-118.

11. Sinitsyn, V. Gostinichnoe delo. 2013. № 09, pp. 50-55.

12. Fridland A.Ya. Information: an overview of modern ideas about the essence and approaches to the definition. Federal portal "United window of the access to educational resource". http://window.edu.ru/catalog/ pdf2txt/804/58804/28666?p_page $=3$

\section{ДАННЫЕ ОБ АВТОРЕ}

Радыгина Евгения Геннадьевна, доцент кафедры туризма и гостеприимства, кандидат педагогических наук, доцент 
Уральский государственньй педагогический университет пр-кт Космонавтов, 26, г. Екатеринбург, Свердловская обл., 620017, Российская Федерачия

radygina@bk.ru

\section{DATA ABOUT THE AUTHOR}

Radygina Evgeniya Gennadievna, associate professor of the pulpit of the tourism and hospitality, candidate of the pedagogical sciences, associate professor

Ural State Pedagogical University

26, Kosmonavtov, Ekaterinburg, Sverdlovsk region, 620017, Russian Federation

radygina@bk.ru

SPIN-code: 8279-8619

ORCID: 0000-0002-2233-7734 